\title{
John M. Daly, MD: The Wise and Gentleman Surgeon
}

\author{
Edward M. Copeland III, MD
}

Department of Surgery, University of Florida College of Medicine, Gainesville, FL

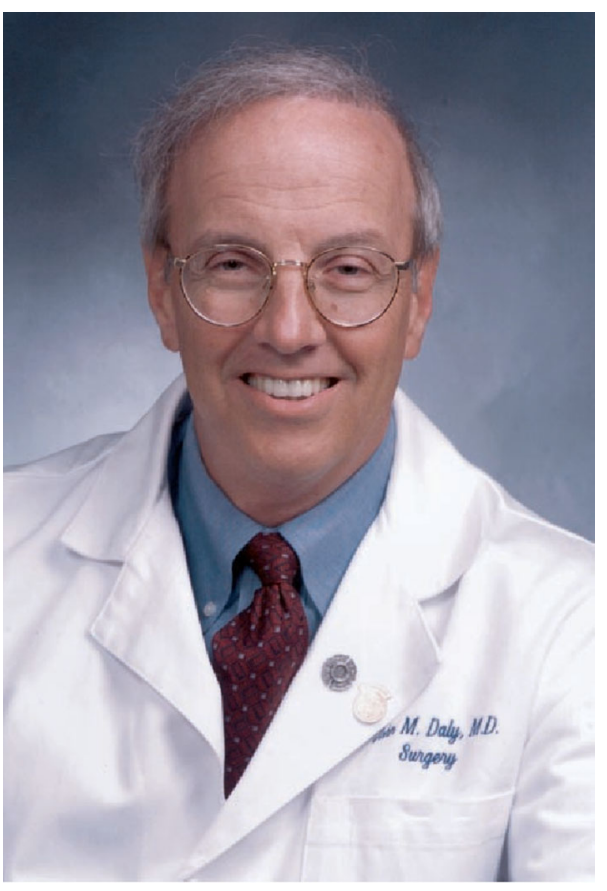

John M. Daly, MD, 1947-2021

John M. Daly passed away unexpectedly on March 26, 2021. On that day, the world of surgery lost one of the brightest, kindest, smartest, and most technically

(C) Society of Surgical Oncology 2022

First Received: 19 January 2022

Accepted: 20 January 2022;

Published Online: 12 February 2022

E. M. Copeland III, MD

e-mail: edward.copeland@surgery.ufl.edu competent leaders in American Surgery. He leaves a legacy of individuals who have risen to prominence in multiple medical specialties, not just in surgical oncology.

Dr. Daly was born on December 10, 1947, in Philadelphia, PA, a town he always considered his home, although he dwelled in other cities such as New York and Houston; and countries, such as Ireland.

When one thinks of Dr. Daly one associates him with the M. D. Anderson Hospital, the University of Pennsylvania, Cornell Medical College, and Temple Medical School. He left his "mark" on all these institutions.

His medical beginning was in Philadelphia. He attended LaSalle College, followed by Temple Medical School. One often wondered why John did not go to Penn. "Too expensive" was his answer. Why do we think of Penn? He applied for a summer research position while at LaSalle. As luck would have it, he joined the research laboratory of Dr. Stanley Dudrick, a graduate of the Penn program. Dr. Dudrick's discovery and development of total parenteral nutrition was in its infancy. John, as a college student, was assigned his own research responsibilities; one of these was comparing the bursting strength on colonic anastomosis in well-nourished versus malnourished animals. This study, presented at the Surgical Forum, helped establish the importance of TPN and began Dr. Daly's life-long interest in the importance of nutritional repletion of malnourished patients.

That experience also led Dr. Daly to his surgical training at the University of Texas Medical School at Houston where Dr. Dudrick had become the Chairman of the Department of Surgery at this new school. Again, as luck would have it, one of the surgical rotations was with Dr. Ted Copeland, who ran the medical school service at MD Anderson. Dr. Daly's first faculty position was at MD Anderson as Dr. Copeland's partner. Here he proved that immune incompetence in many cancer patients was because of malnutrition. Nutritionally replenishing such patients prior to cancer treatment would restore their 
immunocompetence, and thereby he debunked the widely held idea that cancer was the primary cause of the immune deficiency.

From 1982 to 1986, Dr. Daly returned to the Northeast as a faculty member of the Colon and Rectal Service of the Memorial Sloan Cancer Center. Here he added to the developing information on the value of hepatic arterial infusion of chemotherapeutic agents to treat hepatic metastatic disease. In 1986, he presented this data to the joint meeting of the New York Surgical Society and the Philadelphia Academy of Surgery. His presentation was discussed by Dr. Thomas Frazier, another Penn and MD Anderson alumnus.

The chairmanship of surgery at Penn was named for John Rea Barton. Dr. Jonathan Rhoads held this title for the duration of the careers of most of the senior members of the SSO. Thus, the establishment of the Jonathan E. Rhoads Professorship at Penn was a heralded honor. Dr. Daly was recruited to return to Philadelphia as the first Jonathan E. Rhoads Professor and chair of the newly established division of surgical oncology. Here, he encountered colleagues who had also distinguished themselves as master surgeons, especially in the oncologic field. Dr. Daly quickly established a collegial rapport with these individuals and proved that surgical oncology was a distinct specialty within general surgery, and not to the exclusion of any other surgeon with appropriate oncologic expertise. This experience was somewhat pioneering because Dr. Rhoads had considered his trainees to be as adept at surgical oncologic therapy as he had been. Dr. Daly's ability to thrive within these surroundings speaks not only to his surgical competence but also to his inclusive leadership capabilities. These traits were to be on display later in his career at Temple University.

It was also during this time at Penn that Dr. Daly established a working relationship with surgical training programs in Ireland that brought Irish residents to Philadelphia to work in Dr. Daly's laboratory, supported by several RO-1 grants. Many of these trainees have returned to Ireland to lead several surgical programs throughout the country. Dr. Daly was a fellow of the Royal College of
Surgeons in Ireland, and of Glasgow. The T-32 grant that Dr. Daly established at Penn remained for the training of fellows long after Dr. Daly left Penn for his next chapter.

In 1993, Dr. Daly was recruited to become the Chairman of the Department of Surgery at Cornell Medical College. Again, a key point in the history of this school as it forged a partnership with its cross-town rival Columbia Medical School.

John was elected to the Presidency of the Society of Surgical Oncology and the Society of Parenteral and Enteral Nutrition, and to the Vice Presidencies of the American College of Surgeons and the American Surgical Association.

In 2002, after quickly recovering from a liver transplant necessary because of hepatic cirrhosis caused by hepatitis, he turned his energy toward administrative duties as Dean at his alma mater, Temple Medical School. As expected, he greatly advanced the educational experiences of students, and was successful in fundraising for the expansion of the school's facilities. His recovery from the liver transplant was complete. In fact, he often was asked to participate in difficult surgical procedures done at Temple and became a fixture in the OR at Fox Chase Cancer, especially after the loss of his beloved wife, Mary, to cancer, and stepping down as Dean at Temple.

Dr. Daly's success as Dean at Temple is underscored by the institution's insistence that he return as interim Dean in 2018. The interim designation was quickly dropped and was possibly a ploy to get Dr. Daly to return as Dean. He was again happy, remarried to his second wife Palma, with all six children successful, one being a member of the Cornell surgical faculty, when he succumbed to a fatal accident.

The world lost one of its best citizens. His influence reaches much further than his surgical prowess, to the limits of human kindness and understanding.

Publisher's Note Springer Nature remains neutral with regard to jurisdictional claims in published maps and institutional affiliations. 